\title{
Pathology of articular deposition of calcium salts and their relationship to osteoarthrosis
}

\author{
DRA GOSLAVR. MITROVIC \\ From the Department of Cartilage Biology, U-18 of INSERM, Lariboisière Hospital, Paris.
}

Since the reports of Zitnan and Sitaj in $1963,{ }^{1}$ articular chondrocalcinosis, also known as calcium pyrophosphate dihydrate (CPPD) crystal deposition disease, ${ }^{2}$ is now a well recognised clinical entity. It is characterised by intra-articular deposition of CPPD crystals, which encrust hyaline and fibrocartilages, synovium and sometimes intra-articular ligaments.

The common finding of crystals in synovial fluid provides a simple clinical test for assessing the microcrystalline nature of an acute pseudogout attack, ${ }^{34}$ the latter being a characteristic, though not most common, clinical feature associated with chondrocalcinosis. $^{2}$

Numerous radiological and clinical reports have established three major circumstances that may influence the appearance of intra-articular calcification or a pseudogout attack.

Occasionally, it is a familial disorder ${ }^{1}{ }^{\text {5-11 }}$ with an autosomal dominant mode of transmission established in a few kindreds. ${ }^{6-8}$ More often, it is a sporadic disease of adults usually found in association with hyperparathyroidism, ${ }^{12-15}$ haemochromatosis, ${ }^{16-19}$ Wilson's disease, ${ }^{20}$ ochronosis $^{21} 22$ and other hormonal and metabolic disorders. ${ }^{23}{ }^{24}$ Of interest, though of minor importance, are those cases associated with hypophosphatasia ${ }^{25}$ and hypomagnesaemia. ${ }^{26}{ }^{27}$ Trauma has been given as the explanation for meniscal calcifications and more recently chondrocalcinosis of the knee has been linked to meniscectomy. ${ }^{28}$

An unusually high incidence of chondrocalcinosis is found in the elderly, ${ }^{29-34}$ in whom calcifications often remain clinically silent, ${ }^{35}$ being

Correspondence to Doctor D Mitrovic, U-18 INSERM, 6, rue Guy Patin, 75010 Paris. discovered accidentally or after a pseudogout attack, which may complicate infections, and cardiovascular diseases, ${ }^{36}$ major surgical interventions-particularly parathyroidectomy ${ }^{37}$ - or simply prolonged confinement in bed.

The frequent association of chondrocalcinosis and osteoarthrosis has aroused speculation about the pathophysiology and causal relationship of these two conditions. ${ }^{29-34} 38$ 39 Evidence suggests that CPPD crystal deposition may induce severe arthropathies that resemble osteoarthrosis, particularly in a few familial forms of chondrocalcinosis ${ }^{1}{ }^{7}$ where CPPD crystal deposits affect younger individuals and thus precede the development of osteoarthrotic like arthropathies by many years. Osteoarthrosis of the wrist joint is unusual except in chondrocalcinosis ${ }^{40}$ and is considered by some as the distinct feature of disease. More importantly, certain arthropathies of the large joints follow much more rapid and severe courses when associated with CPPD crystal deposits. ${ }^{41-43}$ Finally, the frequent finding of CPPD crystals in the tissues or synovial fluid of osteoarthrotic joints suggest more than a causal link between these two conditions.

In earlier papers ${ }^{18}{ }^{44}$ we described the histological and histochemical changes that have occurred in the cartilage, menisci, and synovium of the knee joints of two patients affected by sporadic chondrocalcinosis, one of them being associated with haemochromatosis. ${ }^{18}$ In more recent studies $^{34}{ }^{39}$ we have conducted post mortem examination of more than 250 knees searching for articular cartilage, degenerative changes and CPPD crystals deposits. We report here our main conclusions and try to summarise the known data on the pathology of CPPD crystals deposition.

Mineral deposits in articular chondrocalcinosis

Intra-articular mineral deposits, unlike all others found under various physiological or pathological conditions, ${ }^{47}$ are composed of monoclinic and triclinic CPPD crystals. ${ }^{45-48}$ Other forms of calcium salts, such as hydrogen phosphate dihydrate, ${ }^{46}$ hydroxyapatite, ${ }^{46}{ }^{47}$ and occasionally brushite, ${ }^{47}$ or even sodium phosphate were found, but it is still unclear whether such crystals are contaminants from calcified cartilage and bone or are formed during the process of abnormal intra-articular mineralisation. Recent studies have pointed out the possibility of changes in the crystal organisation and structure during in vitro handling of biological materials (S Wilhelm and others, paper presented at 15 th International Congress of Rheumatology, Paris, 1981).

Examined under polarised light, the deposits show weak to strong positive birefringence which disappear after decalcification. Microincineration of the non-decalcified sections followed by dark field examination under reflected light is useful for identifying mineral deposits. Using this technique, we have been able to demonstrate the absence of iron in CPPD tissue deposits in one case of haemochromatosis. ${ }^{18}$

With routine haematoxylin-eosin procedure, deposits appear even on decalcified sections as characteristic intense blue spots. They show only weak metachromasia with toluidine blue $^{44}$ and faintly stain with alcian blue.$^{1844}$ Histochemical procedures for calcium salts give irregular results and usually reveal only small deposits or 
those located at the periphery of large ones.

Seen under the scanning electron microscope, CPPD crystals of various sizes appear as triclinic parallelopiped, rhomboid or rod-like structures. ${ }^{45}$

Under transmission electron microscope, two different types of crystals are reported. ${ }^{48-50}$ Most often the crystals are identified as CPPD monoclinic and triclinic rod-like forms of various sizes. ${ }^{2}{ }^{45} 47$ These crystals are resistant to a variable extent under electron beam, some remain homogenous and opaque while others acquire a foamy like appearance (Fig. 1). ${ }^{48} 49$ The second type of crystals seen on electron microscopy is a structure composed of numerous small electron-dense needles that resemble hydroxyapatite (Fig. 2) ${ }^{50}$ In one of our cases these were seen, as reported elsewhere,$^{50}$ in association with typical electron opaque and foamy CPPD crystals.

In articular chondrocalcinosis deposits are usually located within fibrocartilages and hyaline cartilages of knees, wrists, symphysis pubis, and intervertebral discs, although virtually any joint may be affected. Synovial tissue and intra-articular ligaments are affected less often. ${ }^{51}$ In a few instances CPPD crystal deposits have been reported in extra-articular structures

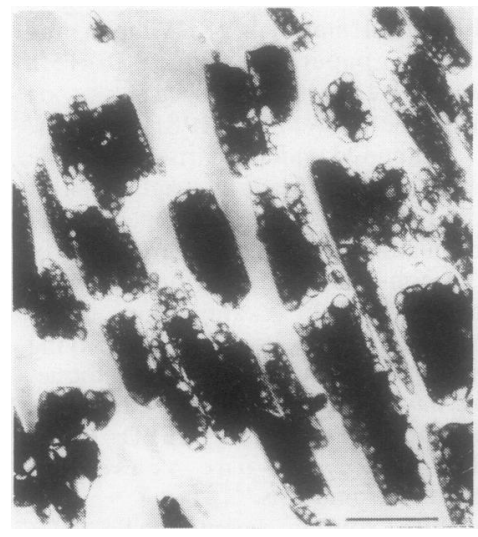

Fig. 1 Cartilagenous CPPD crystal deposit observed on unstained section with transmission electron microscope. The rod-like crystals exhibit bubbled appearance under electron beam. A surrounding material is homogeneous and weakly stained. $H$ and $E \times 48000$ (original magnification). Bar: $0.5 \mu \mathrm{m}$.

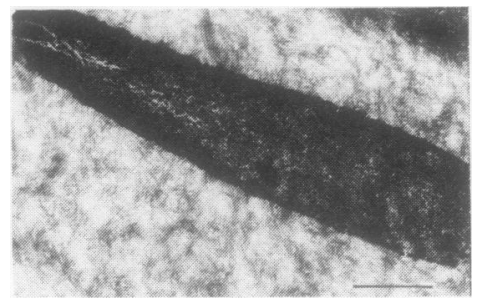

Fig. 2 Structure seen under the electron microscope in articular cartilage that exhibited CPPD and amyloid deposits. The 'crystal' is composed of tightly packed small granules or needles which may resemble hydroxyapatite. Surrounding material is presumably amyloid. Unstained section $\times 24000$ (original magnification). Bar: $1 \mu \mathrm{m}$.

such as ligaments, ${ }^{52-54}$ tendons ${ }^{4755}$ and dura $^{5657}$ In most of these cases, the extra-articular deposits were associated with multiple articular chondrocalcinosis. ${ }^{52-55}$

\section{Meniscal and articular cartilage deposits}

CPPD crystal deposits in the knee joint have been studied thoroughly. In an earlier paper, McCarty et al. described three radiological aspects of meniscal calcifications, presumably corresponding to different types of crystals. ${ }^{46}$ Indeed, using similar methods, we have observed in all but two of 31 joints affected by meniscocalcinosis the aspect shown in Fig. 3 which, according to McCarty et al. should contain CPPD crystals. In one case the calcification had an appearance of ectopic ossification and in the other, it was seen as diffuse

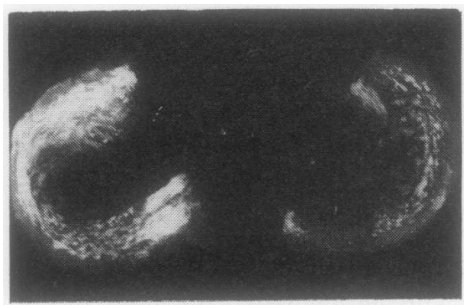

Fig. 3 Roentgenograms using high contrast films ofmenisci of knee joint of 73 year old woman. Mineral deposits appear as irregular granules and lamellae infiltrating $2 / 3$ of the internal portion of menisci (ref.). infiltration of severely damaged medial meniscus. Unfortunately, our preliminary crystallographic analysis of these deposits is too incomplete to come to a definite conclusion about the nature of these crystals.

Under a light microscope, meniscal and chondral calcifications usually are seen as numerous sharply delimited multifocal deposits of various sizes cutting off the matrix beneath the articular surface (Fig. 4). In familial cases and in younger individuals, ${ }^{4858-60}$ the articular surface was reported to be intact. Most cases of sporadic and senile chondrocalcinosis, however, have damaged surfaces. ${ }^{1844} 5059$ The location of the deposits varies from one case to another and from one site in the joint to another. The deposits are sometimes seen as relatively large plaques that may be easily detached, leaving behind an eroded but smooth surface. On histological sections of articular cartilage they may lie under normal and fibrillated surfaces depending on the area chosen for sampling. Usually, fibrillated and vertically fissured cartilage is seen in assocation with rather large deposits and in elderly persons. In menisci of the knee joint, CPPD crystal deposits are usually located in the fibrocartilagenous internal portion beneath the surface of both facets but sometimes they are located more deeply in the tissue. The affected menisci usually look normal except for the presence of CPPD crystal deposits, though in the case of severe

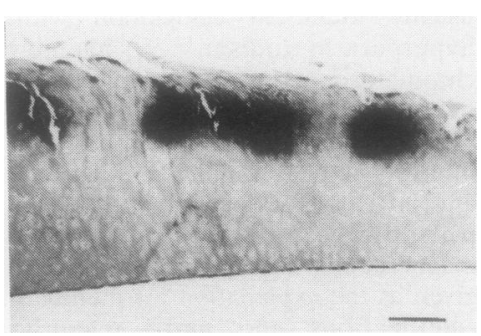

Fig. 4 CPPD crystal deposits (in black) are seen in femoral condylar articular cartilage of 54 year old man affected by haemochromatosis. Deposits lying beneath a fibrillated surface which shows a few vertical clefts. Tissue below deposits has normal appearance. Von Kossa's staining $\times 50$ (original magnification). Bar: $250 \mu \mathrm{m}$. 
osteoarthrosis they may be frayed and deformed. In a few cases of severely damaged articular cartilage and menisci, we have seen CPPD crystal deposits as diffuse infiltrations located exclusively in the superficial fibrillated portion of the tissue. These deposits, unlike the multifocal ones described above, exhibit intense metachromatic staining. Seen under the transmission electron microscope, the CPPD crystals may lie in a matrix of normal appearance, ${ }^{50-52585961-63}$ or be closely packed in some areas (Fig. 5), radiating from the centre of the clusters. ${ }^{48}$ (59 Certain authors have observed CPPD crystals surrounded by an electron dense granular material $^{50}$ and by cell debris. ${ }^{5859}$ This material, seen in two of the menisci, was intensely stained by ruthenium red. ${ }^{\text {so }}$

CPPD crystals were occasionally seen close to cell lacunae ${ }^{5859}$ but never within chondrocytes. Recently, we observed a CPPD crystal within a vacuole of a chondrocyte with a necrotic appearance (Fig. 6). This was, however, in necropsy material and was an isolated finding. In one report CPPD crystals were seen in the calcified layer of articular cartilage lying within a hydroxyapatite impregnated matrix,${ }^{63}$ but this was not confirmed elsewhere. In our experience, the calcified basal layer may be affected by invasion of large crystal deposits from soft uncalcified cartilage.

Changes in articular cartilage and menisci have been reported by several authors. ${ }^{44}$ Usually, a loss of metachromasia of the superficial layer invaded by CPPD crystal deposits is seen in association with cartilage fibrillation. ${ }^{44}$ The chondrocytes may proliferate and form clones that are usually found along the cartilage clefts. Slightly stained zones of matrix degeneration not related to CPPD crystal deposits have also been reported..$^{48} 62$ In one of our sporadic cases, these stained differently from a surrounding matrix, and exhibited no periodic acid Schiff colouration. Seen under electron microsopy, abnormal areas of uncalcified matrix contained fragmented collagen fibres and matrix of a higher electron density. ${ }^{58}{ }^{62}$ The chondrocytes were studied histochemically in one case of sporadic chondrocalcinosis associated with

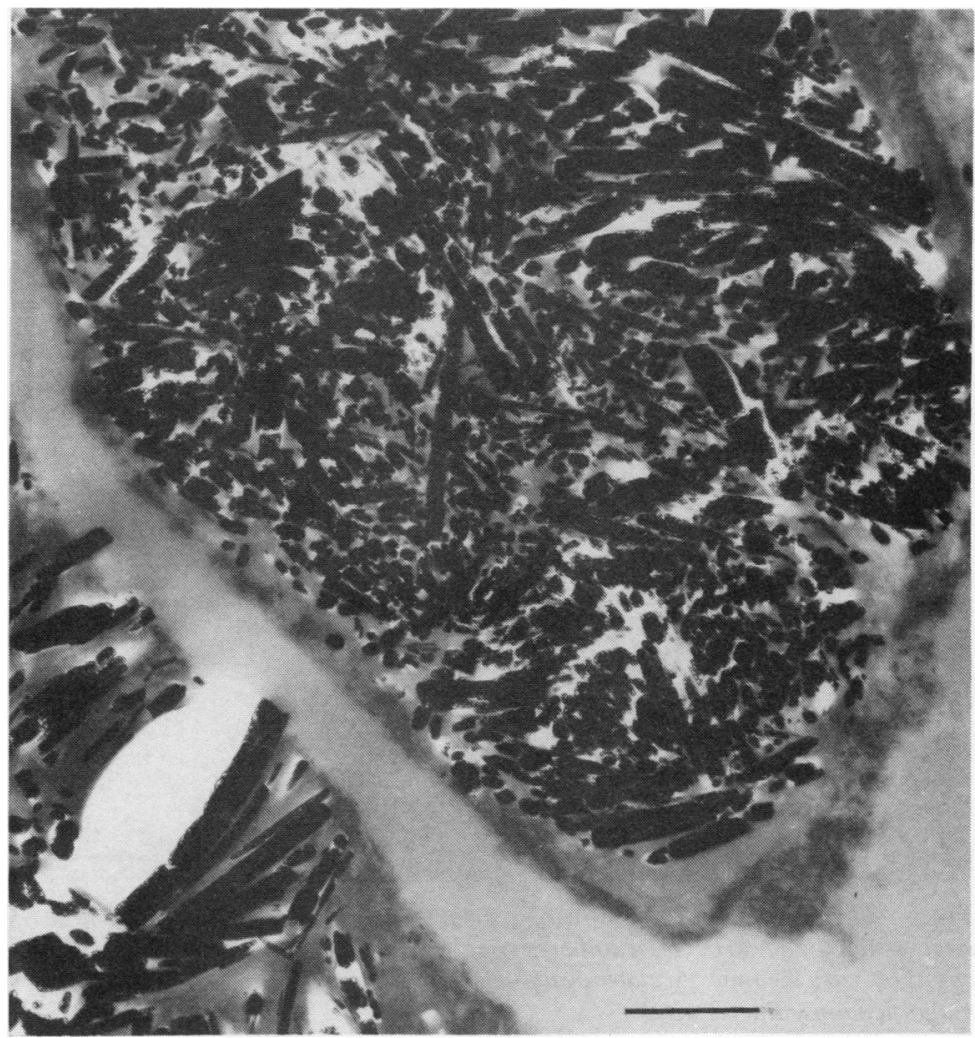

Fig. 5 Electron micrograph of unstained section showing CPPD crystal deposit in articular cartilage. Electron opaque rod-like crystals of various sizes are running in all directions inside an area surrounded by a rim of condensed matrix and almost devoid of other visible material. However, in areas of lower crystal density an homogenous hyaline matrix, presumably collagen, is present in between the crystals. $\times 20400$ (original magnification). Bar: $1 \mu \mathrm{m}$.

haemochromatosis. ${ }^{18}$ It was found that the cells located between CPPD crystal deposits were larger, had a higher content of acid proteins and sulphydryl groups, and were surrounded by a rim of periodic acid Schiff + material. As these cells were loaded with iron-containing material, it was not possible to ascribe these changes to the presence of CPPD crystals. Necrotic chondrocytes have frequently been found close to CPPD crystal deposits. ${ }^{48-50} 585962$

\section{Synovial deposits}

Synovial deposits are not as common or extensive as meniscal and chondral calcifications in chondrocalcinosis. When found (three out of 22 joints in our experience) they are usually seen in the fibrous tissue as round or oval, sharply delimited calcifications, and as diffuse deposits infiltrating superficial synovioblastic and subintimal layers. Most often these calcifications do not induce any cell changes. In one case they were found in the superficial subintimal layer and were surrounded by numerous histiocytic and multinucleated giant cells, which resembled small tophi. Fibrin and discrete perivascular cell infiltrates were present. The synovium of 21 knee joints affected by senile meniscochondrocalcinosis compared histologically with that of joints of normal subjects matched for age, revealed no significant difference in the intensity of synovial inflammation. ${ }^{64}$ 


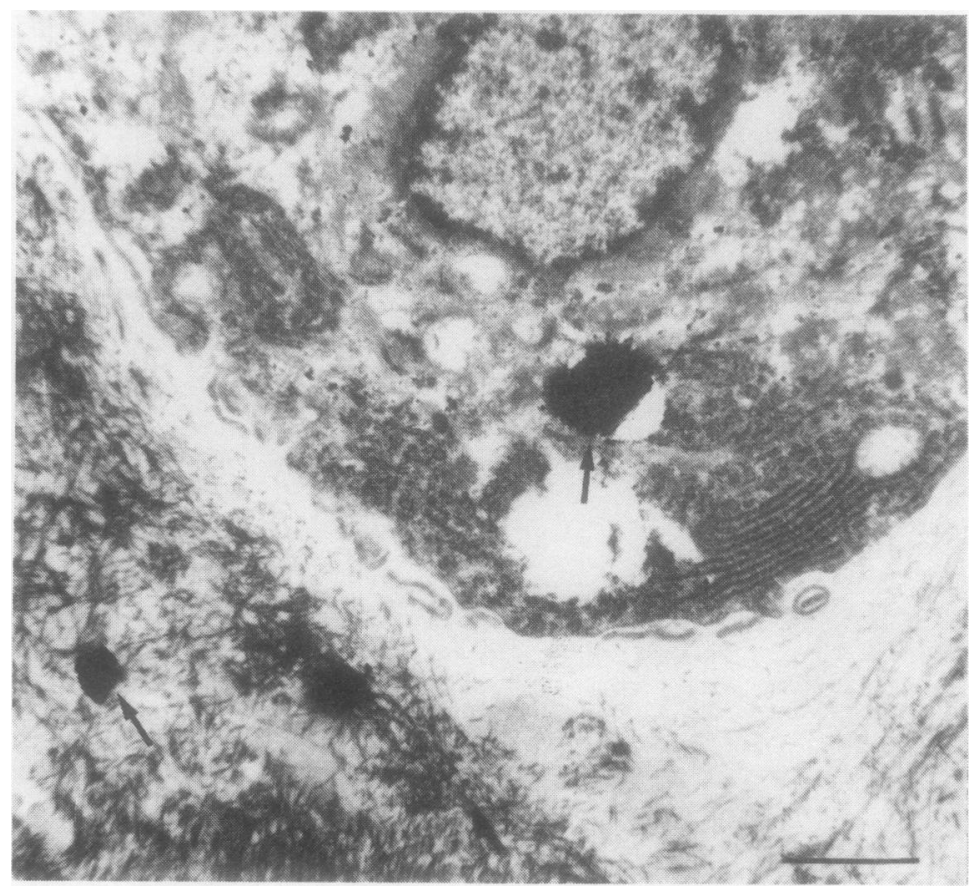

Fig. 6 Electron micrograph showing typical CPPD crystal (arrow) in vacuole of a rather active chondrocyte. Another crystal (arrow) is present in matrix next to the chondrocyte's lacunae. Acetate uranyl-lead citrate staining. $\times 11200$ (original magnification). Bar: $2 \mu \mathrm{m}$.

In a few cases with intra-articular CPPD deposits, clusters of crystals were seen under polarised light in the superficial synovioblastic layer. ${ }^{47}$ so Ultrastructural studies performed on the synovium in the CPPD joints usually revealed the presence of crystals in the interstitial space ${ }^{44}$ and in the vacuoles of macrophage-like synovioblasts, ${ }^{49-5065-67}$ but only occasionally in the endoplasmic reticulum of secretory cells, ${ }^{50}$ suggesting their possible local production.

\section{Synovial fluid deposits}

These crystals are often found on simple microscopical examination of a drop of unstained synovial fluid. This has become a useful clinical test for establishing CPPD crystal deposition disease. $^{3}$ 4 CPPD and, on a few occasions, hydroxyapatite ${ }^{68-71}$ crystals are most often found in the vacuoles of polymorphonuclear and mononuclear macrophage-like cells. They disappear on addition of a few drops of acetic acid or a solution of edetic acid, so that they may easily be differentiated from monosodium urate crystals. ${ }^{34}$

The origin of crystals in the synovial fluid is not known. Most investigators believe that these crystals derive from articular cartilage and menisci by shedding of the deposits. They may, however, be formed in synovial fluid by the crystallisation of soluble CPP salts. $^{72}$

When calcium hydroxyapatite crystals are identified, they may, at least in part, derive from the calcified layer of articular cartilage and subchondral bone. In severe destructive arthropathies, the resorption of calcified osteocartilagenous fragments by the synovial cells (Fig. 7) is a common finding. ${ }^{73}$

Ultrastructural studies have shown that CPPD crystals occur in the vacuoles of phagocytic cells together with other engulfed material such as fibrin, immunoglobulins, and cell debris. ${ }^{495074}$ The membrane preservation of phagocytic vacuoles

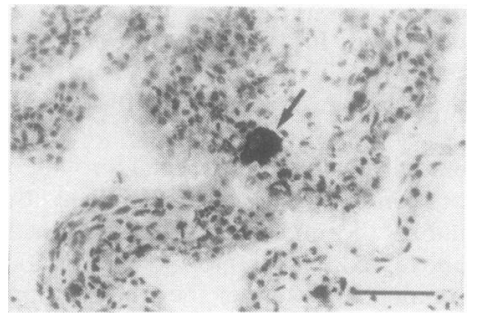

Fig. 7 Synovium taken from an osteoarthrotic knee joint. Several osteocartilaginous fragments (arrow) are seen per section. No calcifications were recorded in menisci and articular cartilage. $H$ and $E \times 300$ (original magnification). Bar: $50 \mu \mathrm{m}$.

that contain crystals was found to be satisfactory, but in vitro studies have suggested that CPPD crystals may induce a membranolytic effect though to a much lesser extent than monosodium urate crystals. ${ }^{75}$

CPPD crystals may absorb proteins such as IgG and induce phagocytosis through surface $\mathrm{Fc}$ receptor sites, or they may activate Hageman factor and complement. ${ }^{76}$ The addition of CPPD crystals to the culture medium induces an appreciable increase in the production and release of collagenase, neutral proteases, and prostaglandins by human rheumatoid and normal rabbit synovioblasts, though the effect is much more pronounced in the presence of calcium hydroxyapatite crystals. ${ }^{77}$ The phlogistic action of CPPD crystals is treated in more detail elsewhere in this issue.

\section{Relationship between CPPD crystal deposits and osteoarthrosis}

Clinical and radiological evidence suggests a relationship between CPPD crystal deposits and osteoarthrosis. The possible undermining effect of CPPD crystals deposits on the anatomical integrity of articular cartilage and other joint tissues does not rule out the existence of more specific interactive processes that may favour either CPPD crystal formation or cartilage degeneration.

Chondrocalcinosis appears to be an independert clinical entity in the familial forms of disease where young individuals are affected. In such cases the occurrence of CPPD crystal deposits in anatomically normal tissue is followed by the development of 
degenerative-like arthropathies which appear in the later stages of disease, probably as a result of both their undermining effect and crystal-induced inflammation. ${ }^{17}$

The problem is more difficult to analyse in sporadic and senile chondrocalcinosis. Arthropathies are common in certain metabolic disorders such as haemochromatosis, ${ }^{16} 19$ ochronosis, ${ }^{21}{ }^{22}$ and Wilson's disease, ${ }^{20}$ which are also known to have high incidence of intra-articular CPPD crystal deposits. Whether such arthropathies develop in the absence of CPPD crystal deposits is not well established. In senile forms of chondrocalcinosis, the frequent association with osteoarthrosis may be accidental and due to the increased incidence of both disorders in elderly individuals. . $^{29-34}$

We examined more than 250 knee joints of unselected cadavers obtained from a pluridisciplinary hospital in Paris. ${ }^{34}{ }^{3964}$ The joints were examined with the naked eye before and after staining their articular surfaces with India ink. Articular and meniscal calcifications and joint lesions were recorded on specially designed drawings. Then the menisci and articular cartilage fragments from femoral condyles were dissected and subjected to radiological and microscopical examination. Multiple synovial fragments were taken from 100 joints of 50 cases.

CPPD crystal deposits were identified by soft $x$-ray radiography of the menisci and cartilage fragments as described previously,,$^{34}{ }^{39}$ and on the histological sections using routine staining procedures and polarised light. The incidence of CPPD crystal deposits, their distribution within the joint and in the tissues, and their relationship to the age and sex of the subjects and to osteoarthrosis, was thus established. Osteoarthrosis was diagnosed in cases of extensive and severe cartilage fibrillation and/or ulceration associated with peripheral osteophytosis. CPPD crystal meniscal and chondral deposits were found in $18.5 \%$ of all subjects: $21 \cdot 5 \%$ of women and $15 \cdot 8 \%$ of men. In about $40 \%$ of these cases meniscocalcinosis was not associated with chondrocalcinosis. In all cases chondral calcification affected the menisci.
In two cases not included in our series, an abundant chalk-like powder deposited on all tissue surfaces was observed in the joint but no calcification was detected on the $\boldsymbol{x}$-ray films of menisci and cartilage fragments. This material may have been present on the surface and not within the tissue and might therefore have been lost while processing the tissue. Unfortunately, we were not able to perform any identification studies on this material.

The mean age of the subjects affected by CPPD crystal deposits was 78 years for men and 82 years for women. The incidence of deposits increased with age: none was seen in those under 60; the incidence then rose to $11 \cdot 7 \%$ in those aged $60-69$, $21 \cdot 2 \%$ in those aged $70-79,26.9 \%$ in those aged $80-89$ and $50 \%$ in those aged over 90 years. In all those over 80 , the incidence was $32 \%$. The mean age of the subjects affected by meniscal deposition without chondral calcifications was slightly, but insignificantly, lower. Lateral menisci were more often affected.

Calcifications were seen more frequently on condyles than in the femoropatellar joint, which was affected in about $20 \%$ of all cases.

Calcifications were usually found in fibrillated areas of articular cartilage: apparently normal surrounding cartilage was also affected but to a much lesser extent. In addition, $20 \%$ of the joints with meniscal and meniscochondral calcifications were normal.

We attempted to relate the presence of intra-articular CPPD crystal deposits to the degree of knee joint damage. ${ }^{39}$ Out of 78 knees of the subjects below 75 years of age (this age appeared to be critical in our series with respect to CPPD crystal deposition), meniscal or meniscochondral calcifications or both were found in three, femorotibial arthrosis in seven, and cartilage fibrilation (not characterised as osteoarthrosis) in 35 joints. Two out of three joints affected by CPPD deposits were osteoarthrotic, and one showed fibrillation of femoral condyles. In those subjects over 75 years of age (110 knees), CPPD crystal deposits were identified in 35 , femorotibial osteoarthritis in 34 , and fibrillation of condylar articular cartilage in 39 joints. Cartilage fibrillation of the tibial plateau was found in almost all joints but was not considered in this study. In this group 19 out of 35 joints affected by CPPD crystal deposits had femorotibial osteoarthrosis $(54.2 \%)$; four had fibrillated cartilage surfaces, and $12(34.2 \%)$ were normal. In those over 75 years of age who did not have intra-articular CPPD deposits (75 joints), femorotibial osteoarthrosis was found in $15(20 \%)$ and fibrillation in 39 joints. The difference in incidence of osteoarthrosis between those joints with CPPD crystal deposits $(54 \cdot 2 \%)$ and those without (from cases aged over 75) is highly significant $\left(p<0.001, \chi^{2}\right.$ test $)$. The incidence of osteoarthrosis was found to be even higher ( $80 \%)$ in those joints where cartilage deposits were seen.

Not only were osteoarthrotic lesions more frequent in the joints affected by CPPD crystal deposits but these joints appeared to be much more severely damaged.

\section{Discussion}

No definite conclusion could be drawn from the results obtained in the younger subjects, considering the small amount of positive findings. Nevertheless, a high incidence of cartilage fibrillation occurred in the absence of visible CPPD crystal deposits, suggesting that the CPPD crystal deposits are not the cause of fibrillation at least in these cases.

Our findings are in agreement with those of previous reports ${ }^{41-43}$ and clearly show that osteoarthrotic lesions are more common and more severe in the joints affected by CPPD crystal deposits than in those that are not.

Cartilage fibrillation, which is thought to be the initial lesion in osteoarthrosis, may occur, at least in its first stages of development, in the absence of CPPD crystal deposits.

However, CPPD deposits in articular cartilage seem to affect the fibrillated areas more frequently and more heavily, and in a few instances are found exclusively in the superficial fibrillated layer of the tissue. This would suggest that local factors are important in determining the tissue localisation of CPPD crystal deposits, and that fibrillated cartilage somehow predisposes to disease. The finding of 
higher concentrations of inorganic pyrophosphate in the synovial fluid of osteoarthrotic patients ${ }^{78} 79$ and in vitro production by incubates of osteoarthrotic articular cartilage, ${ }^{80}$ would further support this view.

However, as shown in this and previous studies, CPPD crystal deposits may also occur in anatomically normal joints. ${ }^{47-50}$ 58-61 6364 This is all the more significant as cartilage fibrillation is a particularly common phenomenon in patients over 75. However, it is unclear whether the affected tissue is normal or not. Zones of abnormal cartilage matrix coexist with calcified areas and may thus represent the initial lesion in chondrocalcinosis. ${ }^{44} 58 \quad 62$ Recent in vitro studies of CPPD crystal deposition from solution in artificial and cartilage matrices ${ }^{81-83}$ are promising for study into the nature of those local factors which may trigger crystal nucleation and growth.

In conclusion, most current evidence suggests that cartilage fibrillation and CPPD crystal deposition are independent processes. Mineral deposition may, however, cause or accelerate cartilage damage by secondarily altering chondrocyte metabolism or simply by decreasing tissue strength and elasticity. On the other hand, particular disorders in tissue metabolism and structure, not expressed in all cases of osteoarthrotic lesion, may constitute a basic abnormality which would account for CPPD crystal deposition. More biochemical and metabolic studies on selected cases are needed to elucidate these and other unexplained points.

We thank Professor A Ryckewaert for his helpful discussions; Doctors: A Stankovic, J Morin, O I Borda, M Quintero, and M Uzan for their collaboration in recent years; and Mrs F Aprile for typing the manuscript.

This work was supported by the grants ATP No 6978101 and ATP No 7679108 of INSERM

\section{References}

1 Zitnan D, Sitaj S. Chondrocalcinosis articularis. Section I. Clinical radiology study. Ann Rheum Dis 1963; 22, 142-52.

2 McCarty D J. Calcium pyrophosphate dihydrate crystal deposition disease 1975 Arthritis Rheum, 1976; 19, suppl: 275-85.
3 McCarty D J, Kohn N N, Faires J S. The significance of calcium phosphate crystals in the synovial fluid of arthritis patients: the 'pseudogout syndrome'. I. Clinical aspects. Ann Intern Med; 1962; 56: 711-37.

4 Solnica J, Mitrovic D, Kahn M F. L'intérêt de la mise en évidence des formations cristalines dans le liquide synovial: la differenciation morphologique et ultrastructurale des cristaux. Sem Hop Paris 1967; 43: 2573-80.

5 Louyot P, Peterschmitt J, Berthelme P. Chondrocalcinose articulaire diffuse familiale. Rev Rhum Mal Osteoartic 1964; 31: 659-63.

6 Van der Korst J K, Geerards J, Driessens F C M. A hereditary type of idiopathic articular chondrocalcinosis. Survey of a pedigree. Am J Med 1974; 56: $307-14$.

7 Reginato A J, Hollander J L, Martinez $\mathrm{V}$, et al. Familial chondrocalcinosis in the Chiloe Islands, Chile. Ann Rheum Dis 1975; 34: 260-8.

8 Bjelle A, Edvinson U, Hagstram A. Pyrophosphate arthropathy in two Swedish families. Arthritis Rheum 1982; 25: 66-74.

9 Gaucher A, Fauré G, Netter P, Pourel J, et al. Hereditary diffuse articular chondrocalcinosis. Dominant manifestation without close linkage with the HLA system in a large pedigree. Scand J Rheumatol 1977; 6: 217-21.

10 Rodriguez-Valverde V, Tinture T, Zuniga M, Pena J, Gonzales A. Familial chondrocalcinosis. Arthritis Rheum 1980; 23: 471-8.

11 Moskowitz $R$ W, Katz D. Chondrocalcinosis and chondrocalcinosynovitis (Pseudogout syndrome). Analysis of twenty-four cases. Am J Med 1967; 43: 322-34.

12 Bywaters E G L, Dixon A St, Scott J T. Joint lesions of hyperparathyroidism. Ann Rheum Dis 1963; 22: 171-87.

13 Dodds W J, Steinbach H L. Primary hyperparathyroidism and articular cartilage calcification. $A J R$ 1968; 104: 884-93.

14 Serre H, Simon L, Thevenet A, Barjon $M$ C. Hyperparathyroidie et chondrocalcinose articulaire. Journal Belge de Medecine Physique et de Rhumatologie (Bruxelles) 1966; 21: 223-42.

15 Ryckewaert A, Solnica J, Lanham C, Seze $S$ de. Les manifestations articulaires de l'hyperparathyroidie. Presse Médicale 1966; 74: 2599-603.

16 Dorfmann H, Solnica J, Dimenza $\mathrm{Cl}$, Seze $S$ de. Les arthropathies des hemochromatoses. Sem Hop Paris 1969; 8: 516-523.

17 Dymock J W, Hamilton E B, Law J W, Williams R. Arthropathy of haemochromatosis: clinical and radiological analysis of 63 patients with iron overload. Ann Rheum Dis 1970; 29: 469-76.

18 Mitrovic D, Mazabraud A, Jaffres R, et al. Etude histologique et histochemique des lésions articulaires de la chondrocalcinose survenant au cours d'une hémochromatose. Archives d'Anatomie Pathologique (Paris) 1966; 14: 264-70.

19 Seze S de, Hubault A, Kahn M F, Welfling J, Jaffres R, Mitrovic D, Solinica J. Les arthropathies des hemochromatoses. Sem Hop Paris 1966; 42: 2472-82.

20 Boudin G, Pepin B, Hubault A. Les arthropathies de la maladie de Wilson. Rev Rhum Mal Osteoartic 19.74; 10: 594-98.

21 Reginato A J, Schumacher H R, Martinez V A. Ochronotic arthropathy with calcium pyrophosphate crystal deposition. A light and electron microscopic study. Arthritis Rheum 1973; 16: 795-814.

22 Rynes R I, Sosman J L, Holdsworth L E. Pseudogout in ochronosis. Arthritis Rheum 1975; 18: 21-5.

23 McCarty D J, Silcox D C, Coe F. Diseases associated with calcium pyrophosphate dihydrate crystal deposition. A control study. Am J Med 1974; 56: 704-14.

24 Sany J, Rosenberg F, Bataille F R, Serre $\mathrm{H}$. Chondrocalcinoses secondaires et associées. Rev Rhum Mal Osteoartic 1977; 44: 565-77.

25 O'Duffy J K. Hypophosphatasia associated with pyrophosphate dihydrate deposits in cartilage. Arthritis Rheum 1970; 13: 381-8.

26 Rapado A, Castillo J M, Abad J A. Chondrocalcinosis e hypomagnesemia: un nuevo syndrome. Rev Esp Rhum Enferm Osteoartic 1976; 3: 283-91.

27 Milazzo S C, Ahern M J, Cleland L G, Henderson $D R$ F. Calcium pyrophosphate deposition disease and familial hypomagnesemia. J Rheumatol 1981; 8: 767-71.

28 Doherty M, Watt I, Dieppe P A. Localised chondrocalcinosis in post-meniscectomy knees. Lancet 1982; i: $1207-10$.

29 Ellman $M H$, Levin D. Chondrocalcinosis in elderly persons. Arthritis Rheum 1975; 18: 43-7.

30 Delauche M C, Stehle E, Cassou B, Verret J M, Kahn M F. Frequence de la chondrocalcinose radiologique après $\mathbf{8 0}$ ans. Une étude prospective. Rev Rhum Mal Osteoartic 1977; 44: 555-7.

31 Memin $\mathrm{Y}$, Monville $\mathrm{Cl}$, Ryckewaert A. La chondrocalcinose articulaire après 80 ans. Rev Rhum Mal Osteoartic 1978; 45: $77-82$.

32 Leonard A, Solnica J, Cauvin M, et al. La chondrocalcinose: étude de sa fréquence radiologique et de ses rapports avec l'arthrose. Etude du taux 
de parathormone. Rev Rhum Mal Osteoartic 1977; 44: 559-64.

33 Megard M, Vignon E, Arlot M, et al. Etude de la chondrocalcinose articulaire dans une population de 200 vieillards. Ses liaisons avec l'antigène HLA. Les relations avec l'arthrose. Lyon Médicine 1981; 245: 365-70.

34 Mitrovic D, Stankovic A, Morin J, et al. Fréquence anatomique de la ménisco-chondrocalcinose du genou. Rev Rhum Mal Osteoartic 1982; 49: 495-99.

35 Emeriau J P, Borde C, Chapoulart H, et al. Chondrocalcinose articulaire asymptomatique chez le sujet âgé. Bordeaux Médicine 1977; 10: 825-30.

36 O'Duffy J D. Clinical studies of acute pseudogout attacks. Arthritis Rheum 1976; 19: 349-52.

37 Glass J S, Graham R. Chondrocalcinosis after parathyroidectomy. Ann Rheum Dis 1976; 35: 521-29.

38 Dieppe P A, Doyle D V, Huskisson E C, Willoughby D A, Crocker P R. Mixed crystal deposition disease and osteoarthritis. Br Med J 1978; i: 150.

39 Stankovic A, Mitrovic D, Morin J, Memin Y, Seze S de, Ryckewaert A. Relation entre la chondrocalcinose articulaire et l'arthrose du genou chez le sujet âgé. Rheumatology 1982; 34: 35-9.

40 Utsinger P D, Resnick D, Zvaifler N J. Wrist arthropathy in calcium pyrophosphate dihydrate deposition disease. Arthritis Rheum 1975; 18: 485-92.

41 Menkes C J, Simon F, Churaki M, Ecoffet M, Amor B, Delbarre F. Les arthropathies destructives de la chondrocalcinose. Rev Rhum Mal Osteoartic 1973; 40: 115-23.

42 Richards A J, Hamilton E B D. Destructive arthropathy in chondrocalcinosis articularis. Ann Rheum Dis 1974; 33: 196-203.

43 Villiaumey J, Galle P, Amouroux J, Larget-Piet B, Rotterdam M, Dimenza C. Arthropathies lytiques et chondrocalcinose articulaire. Sem Hop Paris 1974; 50: 3175-3190.

44 Seze S de, Fressinaud L, Beeson J, Mazabraud A, Mitrovic D. Etude anatomo-clinique d'un cas de chondrocalcinose articulaire diffuse. Sem Hop Paris 1963; 39: 1515-25.

45 Gaucher A, Fauré G, Netter P, Malaman B, Steinmetz J. Identification of microcrystals in synovial fluids by combined scanning electron microscopy and $\mathrm{x}$-ray diffraction: application to triclinic calcium pyrophosphate dihydrate. Biomedicine 1977; 27: 242-4.

46 McCarty D J, Hogan J M, Gatter R A, Grossman M. Studies on pathological calcifications in human cartilage. I. Prevalence and type of crystal deposits in the menisci in two hundred and fifteen cadavera. J Bone Joint Surg [Am] 1966; 48: 309-25.

47 Lagier R. L'approche anatomo-pathologique du concept de chondrocalcinose articulaire. Rheumatology 1981; 23: 421-37.

48 Bjelle A O. Morphological study of articular cartilage in pyrophosphate arthropathy. Chondrocalcinosis articularis or calcium pyrophosphate dihydrate crystal deposition disease. Ann Rheum Dis 1972; 31: 449-56.

49 Reginato A J, Schumacher H R, Martinez V A. The articular cartilage in articular chondrocalcinosis. Arthritis Rheum 1974; 17: 977-92.

50 Schumacher H R. Ultrastructural findings in chondrocalcinosis and pseudogout. Arthritis Rheum 1976; 19: 413-25.

51 Bywaters E G L. Calcium pyrophosphate deposits in synovial membrane. Ann Rheum Dis 1972; 31: 219-1.

52 Bywaters E G L, Hamilton E B D, Williams $R$. The spine in idiopathic haemochromatosis. Ann Rheum Dis 1971; 30: 453-65.

53 Dehais J, Senegas J, Bauduceau B, Bulier R, David-Chausse J. Sténose du canal rachidien lombaire au cours d'une chondrocalcinose articulaire diffuse. Rev Rhum Mal Osteoartic 1977; 44: 585-8.

54 Ellman M H, Vazquez T, Fergusson L, Mandel N. Calcium pyrophosphate deposition in ligamentum flavum. Arthritis Rheum 1978; 21: 611-3.

55 Gerster J C, Lagier R, Boivin G. Achilles tendinitis associated with chondrocalcinosis. J Rheumatol 1980; 7: 82-8.

56 Baud C A. Etude biophysique des calcifications intra-craniennes. J Belge Radiol 1973; 56: 265-9.

57 Grahame R, Sutor D J, Mitchener M B. Crystal deposition in hyperparathyroidism. Ann Rheum Dis 1971; 30: 597-604.

58 Bjelle $\mathrm{A} O$. Articular cartilage in hereditary pyrophosphate arthropathy. Morphological and biochemical studies. Rheumatology 1981; 33: 439-51.

59 Bjelle A O, Sundström K G B. An ultrastructural study of the articular cartilage in calcium pyrophosphate dihydrate (CPPD) crystal deposition disease (chondrocalcinosis articularis). Calc Tiss Res 1975; 19: 63-71.

60 Vignon E, Vignon G. La chondrocalcinose articulaire diffuse. Lyon Médicine 1977; 238: 283-92.

61 Ducastelle $\mathrm{Ch}$, Hemet J, Deshayes P. Introduction anatomopathologique à l'étude de la chondrocalcinose. Rev Rhum Mal Osteoartic 1978; 45: 107-10.

62 Bjelle A O. Cartilage matrix in hereditary pyrophosphate arthropathy. J Rheumatol 1981; 8: 959-64.

63 Botvin G, Lagier R, Baud D. Aspects ultrastructuraux de la chondrocalcinose articulaire. Résultats préliminaires Rheumatology 1981; 33: 127-30.

64 Stankovic A. Struktume histohemijskei biohemiske promene u Zglobnium tkivima. Nis, Yugoslavia: Faculty of Medicine, 1981. Thesis (in Serbo-Croat).

65 Schumacher $H$ R. The synovitis of pseudogout: electron microscopic observation. Arthritis Rheum 1968; 11: 426-35.

66 Moskowitz R W, Harris B K, Schwartz $A$, et al. Chronic synovitis as a manifestation of calcium crystal deposition disease. Arthritis Rheum 1971; 14: 109-116.

67 Kariya M, Terayama K, Taguchi Y, et al. A study of crystal induced synovitis. Thirty three cases of calcification of the menisci of the knee joint. Journal of the Japanese Orthopaedic Association 1970; 44: 1099-113.

68 Dieppe P A, Huskisson E C, Crocker P, Willoughby D A. Apatite deposition disease: a new arthropathy. Lancet 1976; i: $266-8$.

69 Halverson P B, McCarty D J. Identification of hydroxyapatite crystals in synovial fluid. Arthritis Rheum 1979; 22: 389-95.

70 Schumacher H R, Miller J L, Ludovico C, Jessar $\mathbf{R}$ A. Erosive arthritis associated with crystal deposition. Arthritis Rheum 1981; 24: 31-7.

71 Fam A G, Pritzker K R H. Stein J L, et al. Apatite associated arthropathy: a clinical study of 14 cases and of two patients with calcific bursitis. J Rheumatol 1979; 6: 461-71.

72 Doherty M, Dieppe P A. Acute pseudogout: 'crystal sheding' or acute crystallization? Arthritis Rheum 1981; 24: 954-7.

73 Guiraudon C, Bontoux D, Sapporta L. Renseignements fournis par l'examin histologique de la synoviale dans les rhumatismes inflammatoires chroniques. Gazette Médicále de France 1967; 74: 3461-70.

74 Taguchi Y, Kariya M, Terayama K. An electron microscopic study on the synovial cells and the leucocytes in the synovial fluid from pseudogout syndrome. Journal of the Japanese Orthopaedic Association 1968; 42: 1119-29.

75 Mandel N S. The structural basis of crystal-induced membranolysis. Arthritis Rheum 1976; 19: 439-45.

76 Kozin F, McCarty D J. Protein adsorption to monosodium urate, calcium pyrophosphate dihydrate and silica crystals. Relationship to the pathogenesis of crystal induced inflammation. Arthritis Rheum 1976; 19: 433-8.

77 Cheng H S, Halverson P B, McCarty D J. Release of collagenase, neutral protease and prostaglandins from 
cultured mammalian synovial cells by hydroxyapatite and calcium pyrophosphate dihydrate crystals. Arthritis Rheum 1981; 24: 1338-44.

78 Silcox D C, McCarty D J. Elevated inorganic pyrophosphate concentrations in synovial fluid in osteoarthritis and pseudogout. J Lab Clin Med 19.74; 83: 518-31.

79 Russell R G G. Metabolism of inorganic pyrophosphate (PPi). Arthritis Rheum 1976; 19, suppl: $465-78$.
80 Howell D S, Muntz O, Pita J C, Enis J E. Extrusion of pyrophosphate into extra cell media by osteoarthrotic cartilage incubates. J Clin Invest 1975; 56: 1473-80.

81 Pritzker P H K, Cheng PT, Adams ME, Nyberg S C. Calcium pyrophosphate dihydrate crystal formation in model hydrogels. J Rheumatol 1981; 5: 469-73.

82 Pritzker P H K, Cheng P T, Omar S A Nyberg S C. Calcium pyrophosphate crystal formation in model hydrogels. II. Hyaline articular cartilage as gel. $J$ Rheumatol 1981; 8: 451-5.

83 Cheng PT, Pritzker P H K, Adams ME, Nyberg S C, Omar A S. Calcium pyrophosphate crystal formation in aqueous solutions. J Rheumatol 1980; 7: 609-16. 